\title{
Development of a Quantitative Real-time Nucleic Acid Sequence based Amplification (NASBA) Assay for Early Detection of Apple scar skin viroid
}

\author{
Seong Heo $\mathbb{1 D}^{1,2, \text { 十ै*}^{*} \text {, Hyun Ran Kim }}{ }^{3}$, Hee Jae Lee ${ }^{2,4}$ \\ ${ }^{1}$ Apple Research Institute, National Institute of Horticultural and Herbal Science, Rural Development Administration, \\ Gunwi 39000, Korea \\ ${ }^{2}$ Department of Plant Science, Seoul National University, Seoul 08826, Korea \\ ${ }^{3}$ Horticultural and Herbal Crop Environment Division, National Institute of Horticultural and Herbal Science, Rural \\ Development Administration, Wanju 55365, Korea \\ ${ }^{4}$ Research Institute of Agriculture and Life Sciences, Seoul National University, Seoul 08826, Korea \\ ${ }^{\dagger}$ Current address: Ganghwa Agricultural Technology Service Center, Incheon 23038, Korea
}

(Received on October 7, 2018; Revised on December 24, 2018; Accepted on January 4, 2019)

An assay for detecting Apple scar skin viroid (ASSVd) was developed based on nucleic acid sequence based amplification (NASBA) in combination with realtime detection during the amplification process using molecular beacon. The ASSVd specific primers for amplification of the viroid RNA and molecular beacon for detecting the viroid were designed based on highly conserved regions of several ASSVd sequences including Korean isolate. The assay had a detection range of 1 $\times 10^{4}$ to $1 \times 10^{12}$ ASSVd RNA copies/ $\mu$ l with reproducibility and precision. Following the construction of standard curves based on time to positive (TTP) value for the serial dilutions ranging from $1 \times 10^{7}$ to $1 \times 10^{12}$ copies of the recombinant plasmid, a standard regression line was constructed by plotting the TTP values versus the logarithm of the starting ASSVd RNA copy number of 10-fold dilutions each. Compared to the established RT-PCR methods, our method was more sensitive for detecting ASSVd. The real-time quantitative NASBA method will be fast, sensitive, and reliable for routine

\section{*Corresponding author.}

Phone) +82-32-930-4138, FAX) +82-32-930-3643

E-mail) heoseong@gmail.com

ORCID

Seong Heo

http://orcid.org/0000-0003-4485-8810

(c) This is an Open Access article distributed under the terms of the Creative Commons Attribution Non-Commercial License (http:// creativecommons.org/licenses/by-nc/4.0) which permits unrestricted noncommercial use, distribution, and reproduction in any medium, provided the original work is properly cited.

Articles can be freely viewed online at www.ppjonline.org. diagnosis and selection of viroid-free stock materials. Furthermore, real-time quantitative NASBA may be especially useful for detecting low levels in apple trees with early viroid-infection stage and for monitoring the influence on tree growth.

Keywords : apple scar skin viroid, nucleic acid sequence based amplification, RT-PCR

Handling Editor : Yoon, Ju-Yeon

Apple scar skin viroid (ASSVd) is one of the smallest viroid pathogens infecting pome fruits, especially apple, and causes a significant damage to fruit tree. It belongs to the genus Apscaviroid, having a circular RNA molecule, 329330 nucleotides in length (Yang et al., 1992) and a central conserved region within the central domain of the proposed rod-like secondary structure (Flores et al., 1998). ASSVd is generally transmitted through grafting infected scion or pruning tool like secateurs contaminated with crude sap. It is also transmitted through seeds of infected trees at a low rate (Kim et al., 2006). Intense dappling, scarring or cracking is expressed in fruit skins, not in leaves, stems and the other organs, although viroids exist in the vegetative organs (Kim et al., 2006; Koganezawa et al., 2003). ASSVd was first reported at China (Liu et al., 1957), and has been widespread worldwide including Japan (Ushirozawa et al., 1968), USA (Intl. Commit. Coop. Fruit Tree Virus Res., 1985) and Korea (Kwon et al., 2002). Several methods have been developed for detecting viruses and viroids at early stage of infection to fruit trees. The general 
method for detecting viruses has been indexing, in which the virus is transmitted by grafting or budding to sensitive indicator plants, which then develop identifiable symptoms (Németh, 1986). However, this method requires a lot of time, space, money and experienced labors, and limits the plants to be tested. Enzyme-linked immunosorbent assay (ELISA) using antibodies against specific proteins has widely been used for detecting viruses due to its specificity. Furthermore, ELISA method is not applicable to detect viroids, because they do not possess a coat protein and accordingly no antibodies are available for their detection. However, ELISA often fails because of low virus titers or the inhibitory effects of plant polysaccharides or phenolic compounds (Menzel et al., 2003). Polymerase chain reaction (PCR) has been suggested as an alternative to improve the detection sensitivity and convenience. Especially, multiplex reverse transcription (RT)-PCR has allowed the simultaneous detection of several viruses and viroids in one assay and reduced the costs and time (Hassan et al., 2006). Furthermore, using RT-PCR-probe labeled with digoxigenin, RT-PCR-ELISA system was developed to detect six viroids simultaneously (Shamloul et al., 2002). However, the risk of a carry-over contamination of RNA or DNA still exists in the technique.

Recently, a novel method has been utilized to detect ASSVd, known as reverse transcription loop-mediated isothermal amplification (RT-LAMP) (Lee et al., 2018). This assay amplifies target DNA or RNA with high sensitivity, efficiency and rapidity under the temperature constantly maintained at $62-65^{\circ} \mathrm{C}$. There is no requirement for the process of denaturing double stranded DNA prior to amplification and any other measuring equipment and skillful experts. For these reasons, RT-LAMP has potentially been applied for detecting plant viruses and viroids (Lee et al., 2016).

Nucleic acid sequence based amplification (NASBA) method has been introduced for detecting several plant pathogens (Vašková et al., 2004). NASBA is a sensitive transcription-based amplification system for the specific replication of nucleic acids in vitro (Compton, 1991) and based on isothermal amplification which uses two specific oligonucleotide primers and three enzymes of avian myeloblastosis virus reverse transcriptase, RNase $\mathrm{H}$ and T7 RNA polymerase, working in concert at a low isothermal temperature, generally at $41^{\circ} \mathrm{C}$. This process exponentially amplifies the products producing single-stranded RNA of opposite sense to the original target as the major amplification product (Hibbitts et al., 2003). The amplification products have been detected through a probe-capture hybridization using electrochemiluminescence in molecular beacons.
We have developed real-time quantitative NASBA assay using specific molecular beacon for detecting ASSVd in order to certify disease-free apple cultivars. In this study, the assay and its application for detecting ASSVd in apples (Malus $\times$ domestica) are reported and compared to the results from the established RT-PCR.

\section{Materials and Methods}

Plant materials. Ten scion cultivars (Beni Shogun, Chukwang, Fuji, Gamhong, Hongro, Hwahong, Jonagold, Sansa, Seokwang and Yoko) and ten rootstock cultivars (M.9, M.9 EMLA, M.9 T337, M.26, M.27, Ottawa 1, Ottawa 2, P.2, P.22 and Pajam 4) grown at the orchard of National Institute of Horticultural and Herbal Science (NIHHS) were used in this study. ASSVd-infected scions were collected from infected mother stock. To avoid uneven viroid distribution, leaves were collected from different parts of randomly selected stems from each cultivar.

Isolation of nucleic acids. Viroid RNA was extracted from infected leaves using the NucliSens ${ }^{\circledR}$ Basic Kit (BioMérieux Inc., Durham, NC, USA) based on the modified method of Boom et al. (1990) as recommended by the manufacturer. The leaves were pulverized in a mortar and pestle using liquid nitrogen and then resuspended with $1 \mathrm{ml}$ of NucliSens ${ }^{\circledR}$ lysis buffer consisting of $5 \mathrm{M}$ guanidine isothiocyanate, $0.1 \mathrm{M}$ Tris- $\mathrm{HCl}$ (pH 6.4), $20 \mathrm{mM}$ EDTA, and 1.2\% Triton X100 (w/v) with $2 \%$ polyvinylpyrrolidone. After centrifugation at $16,000 \times g$ for $15 \mathrm{~min}, 600 \mu \mathrm{l}$ of the supernatant was transferred in NucliSens ${ }^{\circledR}$ extractor cartridge supplemented with $50 \mu 1$ silica suspension. Total nucleic acids were extracted with NucliSens ${ }^{\circledR}$ automatic extractor. Briefly, nucleic acids bound on silica were washed twice with $1 \mathrm{ml} \mathrm{NucliSens} \mathrm{B}^{\circledR}$ wash buffer consisting of $100 \mathrm{mM}$ Tris- $\mathrm{HCl}(\mathrm{pH} \mathrm{6.4)}$ ) and $10 \mathrm{M}$ guanidine thiocyanate, twice with $1 \mathrm{ml} \mathrm{70 \%}$ ethanol and once with $1 \mathrm{ml}$ acetone and dried at $56^{\circ} \mathrm{C}$ for $10 \mathrm{~min}$. Purified RNA was eluted in $50 \mu \mathrm{l}$ elution buffer at $56^{\circ} \mathrm{C}$ for $10 \mathrm{~min}$ and stored at $-70^{\circ} \mathrm{C}$ until use.

Primer and molecular beacon design. The ASSVd specific primers, $\mathrm{P} 1$ and $\mathrm{P} 2$, for amplification of the viroid RNA were designed based on highly conserved regions of selected ASSVd isolates and our sequence of ASSVd isolate collected from 'Hongro' cultivar in this study. The alignments were carried out by Clustal W method with Lasergene 7 Megalign (DNAstar, Madison, WI, USA) (Fig. 1). Primers and molecular beacon were designed on the manufacturer's recommendations using the program 

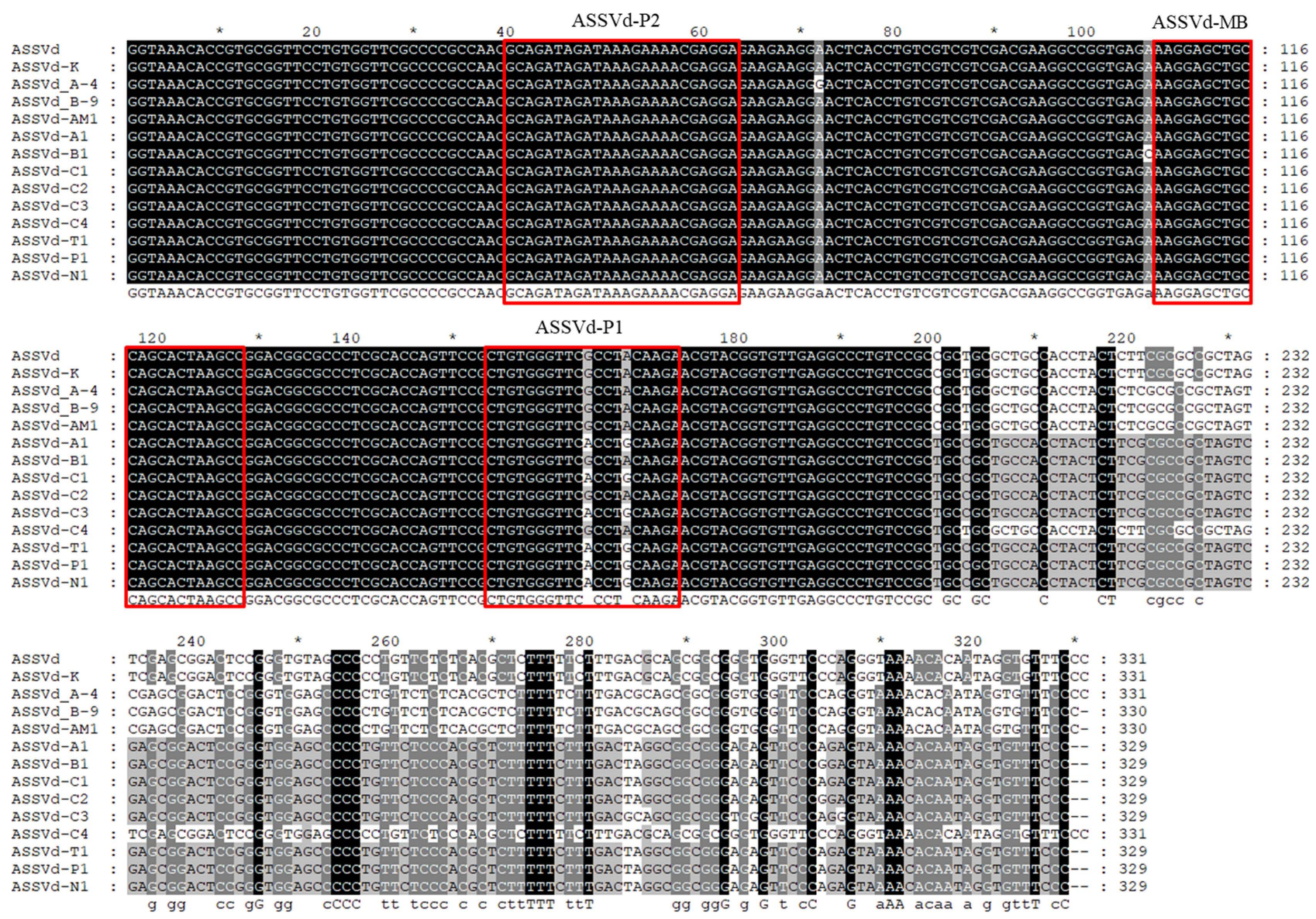

Fig. 1. Nucleotide sequence alignments of ASSVd isolates and the position of ASSVd-specific primers and molecular beacon. Comparison of the nucleotide sequences of ASSVd isolate collected from 'Hongro' cultivar at the orchard of NIHHS with ASSVd-K (Korean strain, accession AF421195), A-4 (DQ362907), B-9 (DQ362906), AM1 (EU031455), A1 (HG764204), B1 (HG764201), C1 (HG764197), C2 (HG764198), C3 (HG764199), C4 (HG764200), T1 (HG764202), P1 (HG764203), N1 (HG764205). ASSVd isolate which identified in this study had $100 \%$ sequence homology with ASSVd-K. Identical nucleic acid residues are shown in black, whereas dashes indicate gaps in the nucleotide sequences introduced to optimize alignment. The primers and molecular beacons sequences for ASSVd are indicated by red rectangles.

Beacon Designer (Premier Biosoft, Palo Alto, CA, USA). Molecular beacon carries a fluorogenic reporter molecule (6-carboxyfluorescein, FAM) at the 5' terminus, while the arm sequence at the 3 ' terminus is covalently linked to a quenching dye (4-(4-4dimethylaminophenylazo)-benzoic acid, DABCYL). Formation of hairpin structure of mo-

Table 1. Sequences of the primers and molecular beacon used in RT-PCR and real-time NASBA assays for detecting ASSVd in apple trees

\begin{tabular}{lll}
\hline \multicolumn{2}{c}{ Primer and probe } & \multicolumn{1}{c}{ Sequence (5' $\left.\rightarrow 3^{\prime}\right)$} \\
\hline RT-PCR $^{\text {a }}$ & ASSVd-F & CCCGGTAAACACCGTGCGGT \\
& ASSVd-R & ACCGGGAAACACCTATTGTG \\
Real-time NASBA & ASSVd-P1 & AATTCTAATACGACTCACTATAGGGAAAGAGCGTGAGAGAACAGG \\
& ASSVd-P2 & GCAGATAGATAAAGAAAACGAGGA \\
& ASSVd-MB & [6-FAM]-CGCGATCaaggagctgccagcactaagccgGATCGCG-[DABCYL] \\
\hline
\end{tabular}

${ }^{a}$ The primers for RT-PCR were reported by Lee et al. (2001).

*Underlined letters indicate the T7 RNA polymerse promoter-binding region. Lowercase letters are the specific binding sequences to ASSVd RNA. 


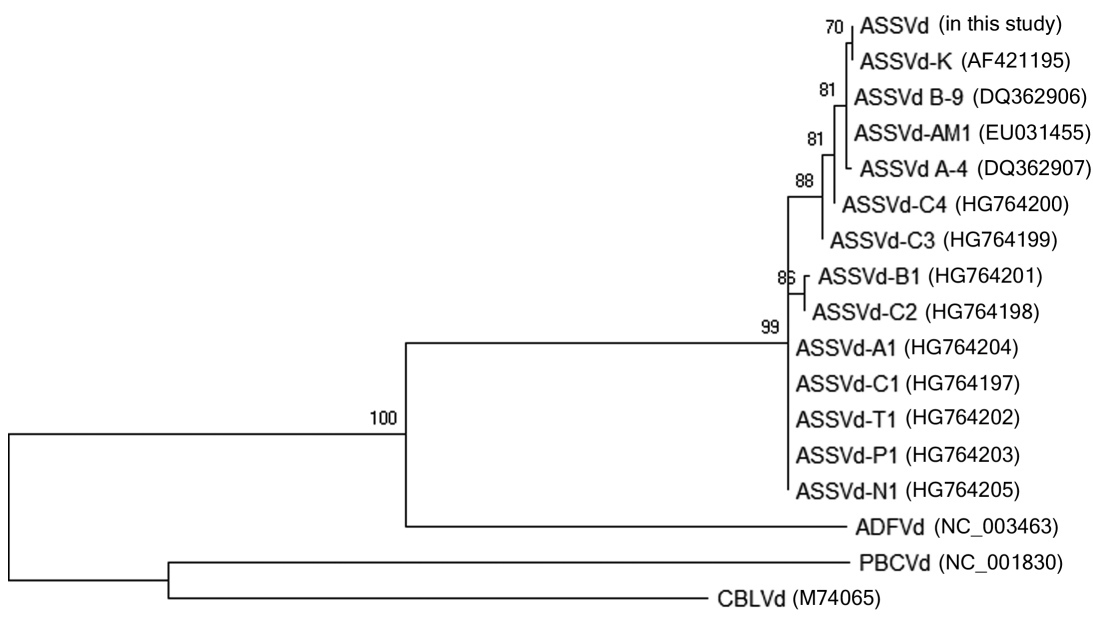

lecular beacon was predicted by the mfold DNA folding program (Zuker and Stiegler, 1981) for single-stranded DNA. Primers and molecular beacon were synthesized and HPLC-purified. The sequences and positions of the primers and molecular beacon were listed in Fig. 1 and Table 1. A dendrogram was constructed using all sequences of ASSVd isolates from the Genbank of NCBI (accessions AF421195, DQ362906, DQ362907, EU031455, EU031456, U031467, EU031477, EU031487, HG764197, HG764198, G764199, HG764200, HG764201, HG764202, G764203, HG764204, HG764205, HQ840722) with our sequence identified in this study (Fig. 2). The ASSVd sequence which is confirmed in this research belonged to the distinct clade which is contained in ASSVd-K with high similarity. Using MEGA X (Kumar et al., 2018) software, we calculated the genetic distance between ASSVd isolates including our sequence and used the maximum likelihood method based on the Tamura-Nei model with 1,000 bootstraps. In dendrogram, ADFVd (NC_003463), CBLVd (M74065), PBCVd (NC_001830) were used as the outgroup of ASSVd isolates belong to the genus Apscaviroid.

RT-PCR. ASSVd-specific forward and reverse primers reported by Lee et al. (2001) were used for the reverse transcription and PCR amplification of ASSVd RNA molecules. RT-PCR was performed in $50 \mu 1$ reaction volume containing $5 \mu \mathrm{l}$ of total RNA, $25 \mu \mathrm{l}$ of $2 \times$ AccessQuick $^{\mathrm{TM}}$ master mix (Promega, Madison, WI, USA), $1 \mu \mathrm{l}$ of $5 \mathrm{U}$ AMV reverse transcriptase, and 33 pmole each primers. Amplification was carried out in a thermocycler (PTC220, MJ Research, St. Bruno, Quebec, Canada). Reaction mixture was incubated at $42^{\circ} \mathrm{C}$ for $70 \mathrm{~min}$. Then PCR was performed at $94^{\circ} \mathrm{C}$ for $5 \mathrm{~min}$, followed by 40 cycles at $94^{\circ} \mathrm{C}$
Fig. 2. A dendrogram which constructed from the sequences of ASSVd isolates; accessions K (AF421195), B-9 (DQ362906), A-4 (DQ362907), AM1 (EU031455), AM2 (EU031456), PP1 (EU031467), PE1 (EU031477), AP1 (EU031487), C1 (HG764197), C2 (HG764198), C3 (HG764199), C4 (HG764200), B 1 (HG764201), T 1 (HG764202), P1 (HG764203), A1 (HG764204), N1 (HG764205), ap (HQ840722), and ADFVd (NC_003463), CBLVd (M74065), and PBCVd (NC_001830) belong to the genus Apscaviroid. It was constructed by the maxium likelihood method based on Tamura-Nei model with 1,000 bootstraps. for $45 \mathrm{~s}, 57^{\circ} \mathrm{C}$ for $30 \mathrm{~s}$ and $72^{\circ} \mathrm{C}$ for $45 \mathrm{~s}$, and final extension for $5 \mathrm{~min}$ at $72^{\circ} \mathrm{C}$. Then, the amplicons of target DNA were examined on agarose gel electrophoresis.

Cloning and in vitro transcription. RT-PCR band was excised from the agarose gel and extracted using QIAquick Gel Extraction Kit (Qiagen, Valencia, CA, USA). PCR product obtained from gel was cloned directly into pGEM-T Easy Vector (Promega, Madison, WI, USA). Plasmids were transformed into competent cells, TOP 10F' (Invitrogen, Carlsbad, CA, USA) by chemical transformation. Transformants were color-screened on Luria-Bertani medium with $50 \mu \mathrm{g} / \mathrm{ml}$ ampicillin, $0.1 \mathrm{mM}$ isopropyl $\beta$-D1-thiogalactopyranoside and $40 \mu \mathrm{g} / \mathrm{ml} \mathrm{X}$-gal, overnight at $37^{\circ} \mathrm{C}$ and the presence of the expected inserts confirmed by colony PCR. Plasmids were purified with High Pure Plasmid Isolation Kit (Roche, Basel, Switzerland). These plasmids were verified by sequencing and plasmid containing the inserts was linearized using restriction enzyme ApaI. Transcripts were generated from an upstream promoter using SP6 RNA polymerase, RNasin ribonuclease inhibitor and Riboprobe in vitro Transcription Kit (Promega, Madison, WI, USA) with $1 \mu \mathrm{g}$ of linearized template DNA in a final reaction volume of $20 \mu \mathrm{l}$ according to the manufacturer's instructions. To remove plasmid DNA, RNasefree DNase was treated and the RNA copy number was estimated by UV spectroscopy at an optical density of 260 $\mathrm{nm}$, using $108,968.6$ as the estimated molecular weight of each deoxynucleotide and Avogadro's number to give copies per mole.

Real-time NASBA. Real-time NASBA was carried out in $20 \mu 1$ reactions using reagents from the NucliSens ${ }^{\circledR}$ 
basic kit, which is the volume recommended by the basic kit protocol. NASBA reactions were started by mixing $5 \mu 1$ of extracted nucleic acid and $10 \mu 1$ of NASBA mix in microtubes. The reaction mixture consisted of $40 \mathrm{mM}$ Tris $\mathrm{HCl}$ ( $\mathrm{pH} 8.5$ ), $12 \mathrm{mM} \mathrm{MgCl} 2,60 \mathrm{mM} \mathrm{KCl}, 5 \mathrm{mM}$ dithiothreitol, $15 \% \mathrm{v} / \mathrm{v}$ dimethyl sulfoxide, $1 \mathrm{mM}$ dNTPs, $2 \mathrm{mM}$ each of rATP, rUTP and rCTP, $1.5 \mathrm{mM}$ rGTP, 0.5 $\mathrm{mM}$ inosine 5'-triphosphate (ITP), $30 \mu \mathrm{M} 3$ primer $\mathrm{P} 1,30$ $\mu \mathrm{M}$ primer $\mathrm{P} 2$, and $10 \mu \mathrm{M}$ molecular beacon. To increase the yield of NASBA products, $2 \mathrm{mM}$ ITP was added in the tubes, because of GC-rich and intramolecular base paired structure of ASSVd (Nakahara et al., 1998). Subsequently, the reaction mixtures were incubated at $94^{\circ} \mathrm{C}$ instead of the standard $65^{\circ} \mathrm{C}$ for $2 \mathrm{~min}$ for denaturation, followed by incubation at $65^{\circ} \mathrm{C}$ for $5 \mathrm{~min}$ and $41^{\circ} \mathrm{C}$ for $5 \mathrm{~min}$. Then, 5 $\mu 1$ of enzyme mix consisting of $375 \mathrm{mM}$ sorbitol, $2.1 \mu \mathrm{g}$ bovine serum albumin, $0.08 \mathrm{U}$ RNase H, $32 \mathrm{U}$ T7 RNA polymerase and 6.4 U AMV reverse transcriptase was added to each tube. The tubes were centrifuged briefly in a microcentrifuge to collect the enzyme mix. After tapping gently, the tubes were incubated at $41^{\circ} \mathrm{C}$ for $150 \mathrm{~min}$. Molecular beacon labeled with FAM was excited at $485 \mathrm{~nm}$, and fluorescence emission was detected at $530 \mathrm{~nm}$.

\section{Results}

Primer and molecular beacon for ASSVd. The sequences were aligned for fourteen ASSVd isolates including Korean isolate that we cloned (Fig. 1). Our cloned sequence had $100 \%$ homology with the sequence of ASSVd-K (AF421195) reported by Lee et al. (2001). Molecular beacon ASSVd-MB was designed to carry 5' end and 3' end sequences of 7 nucleotides complementary to each other and internal sequence of 23 nucleotides complementary to the ASSVd specific NASBA product to hybridize. Secondary structure was confirmed to form hairpin-like loop shape at $41^{\circ} \mathrm{C}$ using mfold DNA folding program.

NASBA condition. To develop real-time NASBA assay, we designed specific primers and molecular beacon for ASSVd, and then these primers were tested for the best performing reaction. The second step was to find out optimal $\mathrm{KCl}$ and ITP concentrations for amplification. For the following steps, twenty samples which were confirmed to be negative for ASSVd were analyzed to define the threshold level for detection. To define the optimal primer concentration, we examined fluorescent signals ranging from 20 to $60 \mu \mathrm{M}$ (Fig. 3A). The primer concentration with the highest analytical sensitivity or with the highest signal should be regarded as the optimal primer concentration for

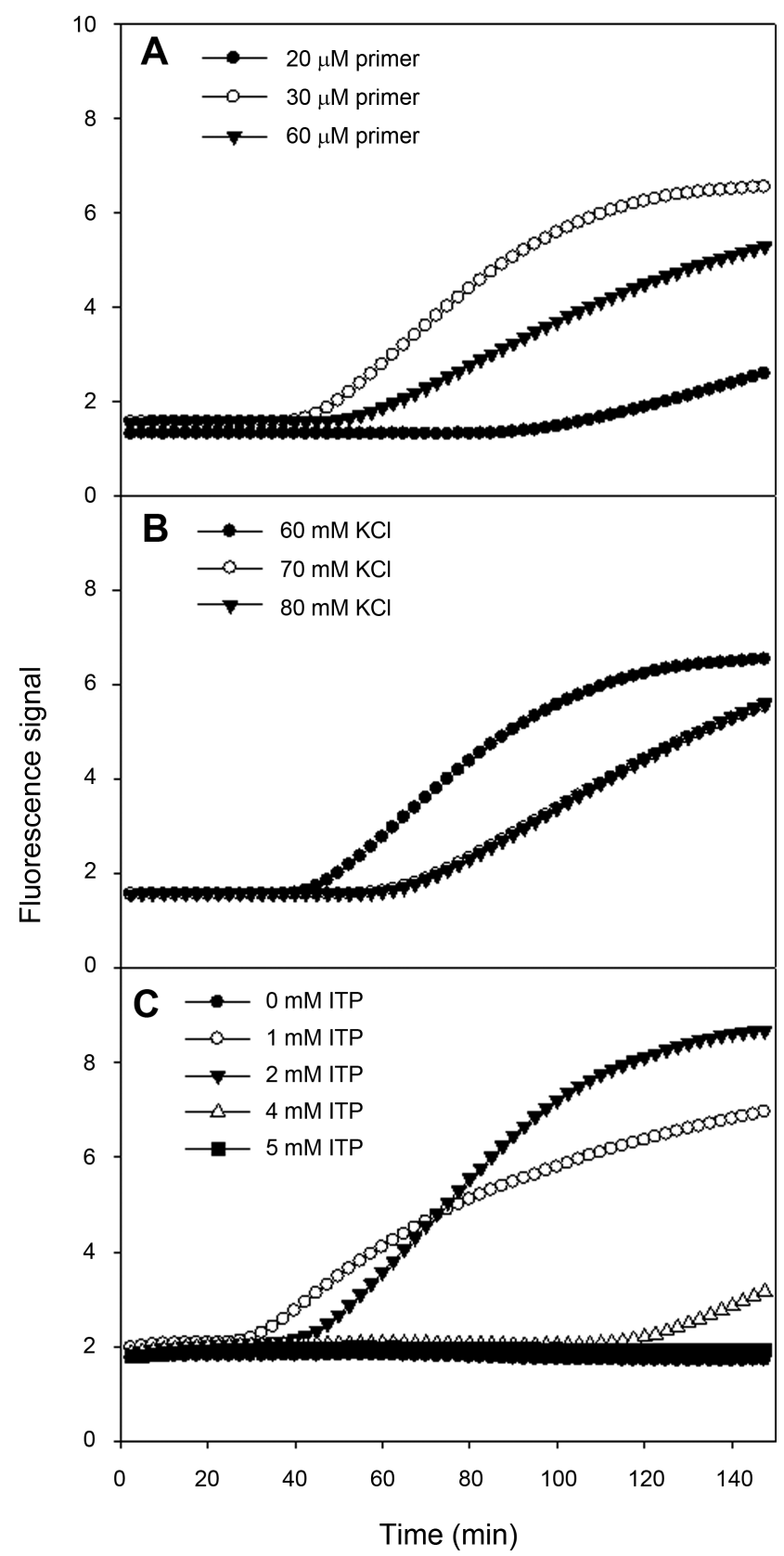

Fig. 3. Sensitivity of ASSVd real-time detection using molecular beacon to determine the optimization of the assay. Optimization of (A) the primers, (B) $\mathrm{KCl}$ and (C) ITP concentration with the highest fluorescent signal or the lowest time to positive (TTP) value.

detecting ASSVd. The optimal primer concentration was found to be $30 \mu \mathrm{M}$. Optimal $\mathrm{KCl}$ concentration, respectively for corresponding primer pair and ITP concentration was $60 \mathrm{mM}$ (Fig. 3B) and $2 \mathrm{mM}$ (Fig. 3C). This assay was optimized at $60 \mathrm{mM} \mathrm{KCl}, 30 \mu \mathrm{M}$ primers, $10 \mu \mathrm{M}$ molecular beacon and $2 \mathrm{mM}$ ITP. The specific primers target and amplify the sequence from ASSVd found in apple fruits. 
In order to reflect as reliable as possible whether a given sample is positive or negative for ASSVd, 20 samples confirmed to be negative for ASSVd were analyzed in four different runs using real-time NASBA. From the highest and lowest baseline fluorescence signals, the ratio and average baseline fluorescence could be used to calculate the threshold level. Subsequently, we have decided threshold level for detection of ASSVd at 1.414 (data not shown).

Quantitative real-time NASBA. The above developed assay could be applied quantitatively by assuming the amount of unknown RNA samples from the standard curve constructed with the known amount of RNA molecules. To construct standard curve based on time-to-positivity (TTP) values, indicating the cycle number in which amplification first enters a logarithm phase like $C_{t}$ value in real-
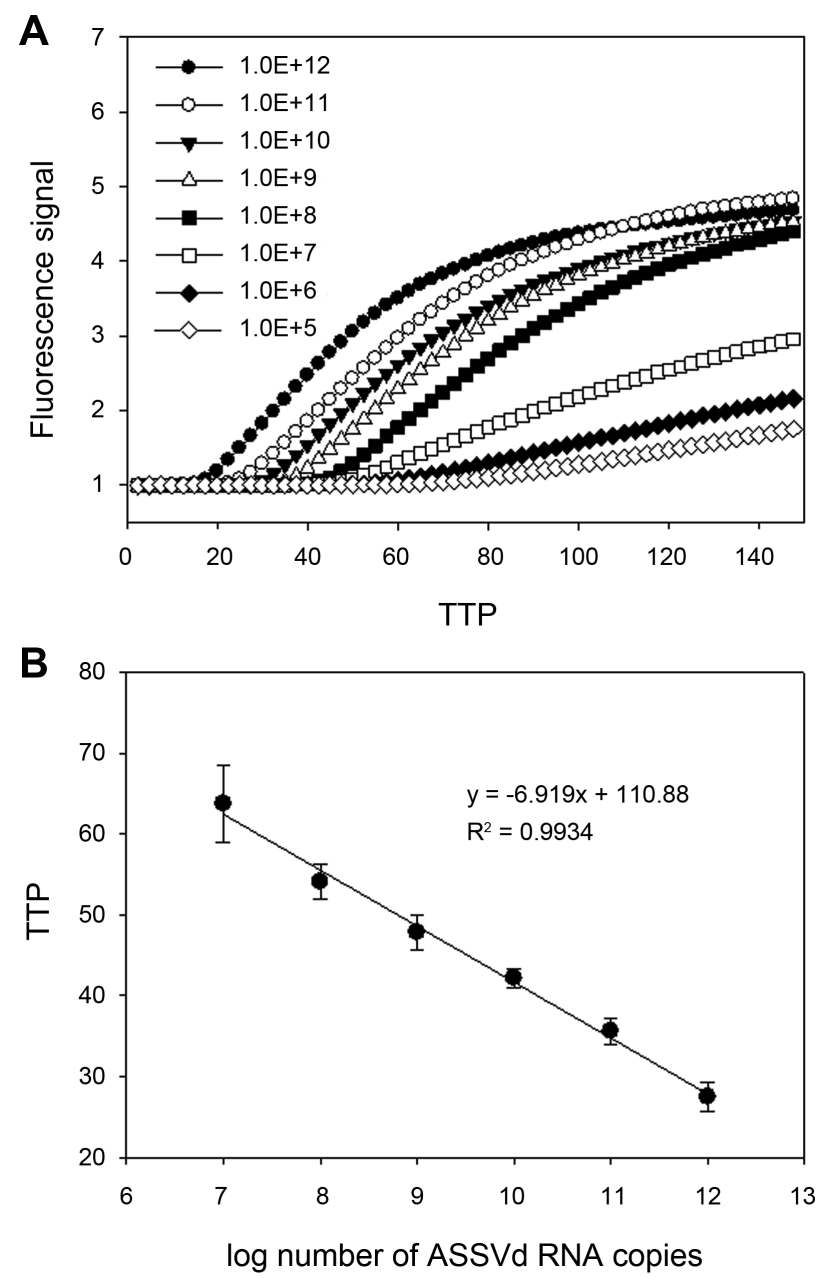

Fig. 4. The standard curve of ASSVd RNA using real-time NASBA. (A) Real-time NASBA amplification plot based on TTP value versus fluorescence. (B) Relationship of TTP to ASSVd RNA copy number. time PCR, dilution series of ASSVd RNA standard were prepared ranging from $1 \times 10^{4}$ to $1 \times 10^{12}$ copies/ $\mu$ l. The fluorescence signals of in vitro synthesized ASSVd RNA were shown in Fig. 4. The intervals between TTP values were consistent over a range of at least six orders of magnitude of RNA molecule from $1 \times 10^{12}$ to $1 \times 10^{7}$, as shown by the decimal dilution series. The limit of detection was determined at $1 \times 10^{5}$ RNA copies for $150 \mathrm{~min}$. A standard regression line was constructed by plotting the TTP values versus the logarithm of the starting ASSVd RNA copy number of 10-fold dilution each. The number of RNA copies present in the reaction was indicated on the $\mathrm{X}$ axis and the TTP value in indicated on the $Y$ axis. TTP values were inversely correlated with the initial copy number of ASSVd RNA. The higher the ASSVd RNA, the less reaction time needs to amplify to a detectable level. For the data ranging from $1 \times 10^{7}$ to $1 \times 10^{12}$ copies, the TTP value was the mean of three independent experiments. Starting template copies lower than $1 \times 10^{7}$ were not consistently amplified. The linear quantification was made between $1 \times 10^{7}$ to $1 \times 10^{12}$ RNA

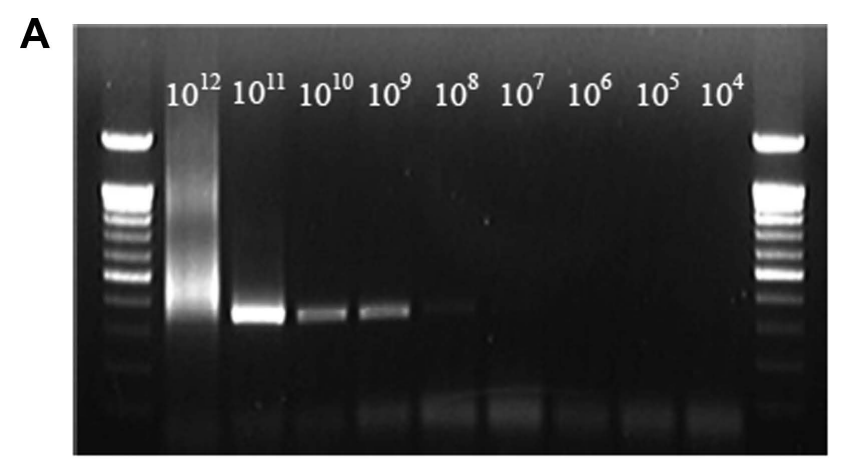

B

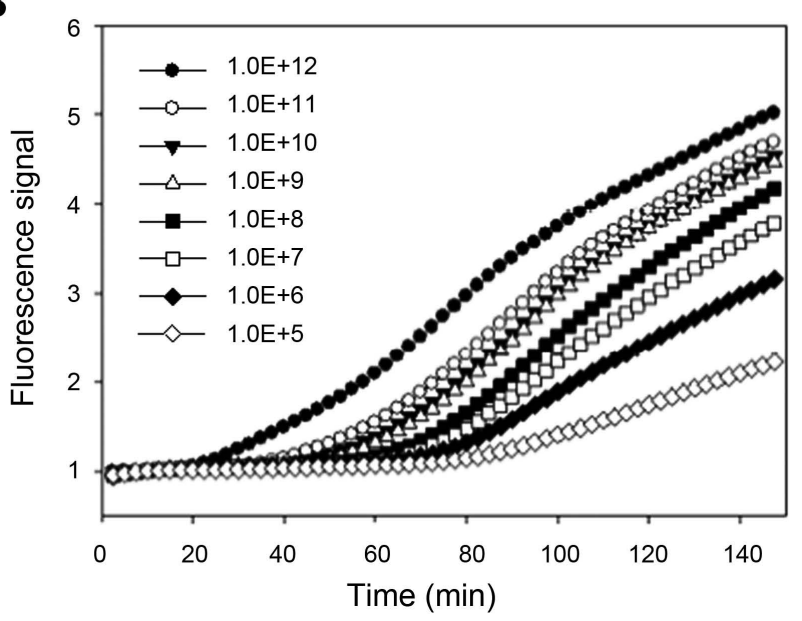

Fig. 5. Comparison of sensitivity to detect ASSVd RNA molecules by RT-PCR and real-time NASBA. (A) End-point detection of ASSVd by RT-PCR. (B) Relative fluorescence with a dilution series by real-time NASBA. 
copies $\left(\mathrm{R}^{2}=0.99, P<0.0001\right)$.

Comparison of real-time NASBA and RT-PCR results. Two different molecular detection systems were compared to verify their performance and analytical sensitivity by using the same diluted RNA samples. General RT-PCR and real-time NASBA were performed according to the established and developed methods above (Fig. 5). With RTPCR, the detection of ASSVd was obtained up to approximately $1 \times 10^{8}$ copies. However, the band was smeared at $1 \times 10^{12}$ copies/ $\mu 1$ and quite obscure in $1 \times 10^{8}$ fold dilution. On the other hand, relative fluorescence with dilution series by real-time NASBA could be detect up to $1 \times 10^{5}$ folds and more sensitive than the established RT-PCR method.

\section{Discussion}

In this study, we reported NASBA assay with real-time detection of ASSVd by molecular beacon using the $\mathrm{Nu}-$ cliSens $^{\circledR}$ Basic Kit, which is an alternative to the existing detection methods. RNA extraction using NucliSens ${ }^{\circledR}$ Lysis Buffer and Isolation Reagents (silica), which was based on the methods of Boom et al. (1990), was more convenient to isolate RNA than other extraction kits. Especially, this isolation method is easy and speedy during high-throughput processing to even non-experienced experimenters. However, this kit was not manufactured anymore according to the company policy. Therefore, we were utilizing NucliSens $^{\circledR}$ easyMAG ${ }^{\mathbb{B}}$ system in the present study.

Real-time NASBA assay developed in this study was optimized to detect ASSVd exquisitely according to the guidance in development of in-house NASBA assay of manufacturer's recommendations. The assay mixture was composed of $60 \mathrm{mM} \mathrm{KCl}, 30 \mu 3$ primers, $10 \mu \mathrm{M}$ molecular beacon and $2 \mathrm{mM}$ ITP. Additional ITP was known to increase the efficiency to swell NASBA products which have GC-rich and intramolecular base-paired viroid RNA (Nakahara et al., 1998). Substitution to "I" from "G" in the sequences was not a serious problem to real-time detect by using molecular beacon.

Real-time NASBA assay was compared to parallel RTPCR assay with respect to detection limits. The results showed that the real-time NASBA assay developed was more sensitive and specific than RT-PCR analysis for the detection of ASSVd in apple trees. Furthermore, this method was faster to perform than RT-PCR and more reliable to detect ASSVd. A set of RNA samples could be analyzed within $2.5 \mathrm{~h}$ by real-time NASBA, faster than RT-PCR method combined with gel electrophoresis and imaging. The employment of molecular beacon permitted precise diagnosis in a single tube, without electrophoresis on gel, imaging and contamination risk. RT-PCR could detect as little as $1 \times 10^{8}$ copies $/ \mu 1$, and was able to analyze in $1 \times 10^{11}$ copies/ $\mu 1$ of in vitro synthesized RNA. However, PCR band was smeared at $1 \times 10^{12}$ dilution, because too many RNAs were included in samples. In the case of $1 \times 10^{8}$ fold dilution, the ASSVd band was barely visible, because RNA was not sufficient to reverse-transcribe or to amplify by polymerase. On the other hand, the real-time NASBA with molecular beacon could detect from $1 \times 10^{12}$ to $1 \times 10^{5}$ copies of ASSVd RNA. The fluorescence signal at $1 \times 10^{4}$ fold dilution could also be detected within $150 \mathrm{~min}$ (data not shown), even with low reproducibility. ASSVd in samples could be quantified by comparing the TTP value of each sample to the TTP values from the standard regression lines. The amount of starting template in any NASBA reaction, expressed as the copy number of the target ASSVd RNA in the original plant extract, could accurately be determined. The limit of quantification (LOQ) for detection of ASSVd was determined at $1 \times 10^{7}$ RNA copies from the results. According to this result, routine diagnosis through above real-time NASBA had better to perform within 90 min than 150 min to detect ASSVd, resulting from range of LOQ. The real-time NASBA assay is easier to use and more specific and faster to detect ASSVd in apple trees compared to RT-PCR assay. Furthermore, this assay might especially be useful for detecting low levels of viroids in apple trees at early infection stage and for monitoring their influence on tree growth. Therefore, this assay might be suitable for high-throughput diagnosis and automation like quarantine, certification and breeding programs for viroid resistance in apple trees.

\section{Acknowledgments}

This research was funded by Rural Development Administration, Korea. The sequences of primer and molecular beacon developed in this study were applied for a patent in Korea by the Rural Development Administration and assigned to the application 10-1024493.

\section{References}

Boom, R., Sol, C. J., Salimans, M. M., Jansen, C. L., Wertheimvan Dillen, P. M. and van der Noordaa, J. 1990. Rapid and simple method for purification of nucleic acids. J. Clin. Microbiol. 28:495-503.

Compton, J. 1991. Nucleic acid sequence-based amplification. Nature 350:91-92.

Flores, R., Randles, J. W., Bar-Joseph, M. and Diener, T. O. 1998. A proposed scheme for viroid classification and nomencla- 
ture. Arch. Virol. 143:623-629.

Hassan, M., Myrta, A. and Polak, J. 2006. Simultaneous detection and identification of four pome fruit viruses by one-tube pentaplex RT-PCR. J. Virol. Methods 133:124-129.

Hibbitts, S., Rahman, A., John, R., Westmoreland, D. and Fox, J. D. 2003. Development and evaluation of Nuclisens ${ }^{\circledR}$ basic kit NASBA for diagnosis of parainfluenza virus infection with 'end-point' and 'real-time' detection. J. Virol. Methods 108:145-155.

Kim, H. R., Lee, S. H., Lee, D. H., Kim, J. S. and Park, J. W. 2006. Transmission of Apple scar skin viroid by grafting using contaminated pruning equipment and planting infected seeds. Plant Pathol. J. 22:63-67.

Koganezawa, H., Yang, X., Zhu, S. F., Hashimoto, J. and Hadidi, A. 2003. Apple scar skin viroid in apple. In: Viroids, eds. by A. Hadidi, R. Flores, J. W. Randles and J. S. Semancik, pp. 137141. CSIRO Publishing, Collingwood, Australia.

Kumar, S., Stecher, G., Li, M., Knyaz, C. and Tamura, K. 2018. MEGA X: Molecular evolutionary genetics analysis across computing platforms. Mol. Biol. Evol. 35:1547-1549.

Kwon, M. J., Hwang, S. L., Lee, S. J., Lee, D. H. and Lee, J. Y. 2002. Detection and distribution of apple scar skin viroidKorean strain (ASSVd-K) from apples cultivated in Korea. Plant Pathol. J. 18:342-344.

Lee, J. H., Park, J. K., Lee, D. H., Uhm, J. Y., Ghim, S. Y. and Lee, J. Y. 2001. Occurrence of apple scar skin viroid-Korean strain (ASSVd-K) in apples cultivated in Korea. Plant Pathol. J. 17:300-304.

Lee, S. H., Kim, Y. H. and Ahn, J. Y. 2016. The detection and diagnosis methods of infectious viroids caused plant diseases. $J$. Life Sci. 26:620-631.

Lee, S. H., Ahn, G., Kim, M. S., Jeong, O. C., Lee, J. H., Kwon, H. G., Kim, Y. H. and Ahn, J. Y. 2018. Poly-adenine-coupled LAMP barcoding to detect Apple scar skin viroid. $A C S$
Comb. Sci. 20:472-481.

Liu, F. C., Chen, R. F. and Chen, Y. X. 1957. Apple scar skin disease. Academia Sinica Printery, Beijing, China. 43 pp (in Chinese).

Menzel, W., Zahn, V. and Maiss, E. 2003. Multiplex RT-PCRELISA compared with bioassay for the detection of four apple viruses. J. Virol. Methods 110:153-157.

Nakahara, K., Hataya, T. and Uyeda, I. 1998. Inosine 5'-triphosphate can dramatically increase the yield of NASBA products targeting GC-rich and intramolecular base-paired viroid RNA. Nucleic Acids Res. 26:1854-1855.

Németh, M. 1986. Virus, mycoplasma, and rickettsia diseases of fruit trees. Springer Netherlands, Dordrecht, The Netherlands. 750 pp.

Shamloul, A. M., Faggioli, F., Keith, J. M. and Hadidi, A. 2002. A novel multiplex RT-PCR probe capture hybridization (RTPCR-ELISA) for simultaneous detection of six viroids in four genera: Apscaviroid, Hostuviroid, Pelamoviroid, and Pospiviroid. J. Virol. Methods 105:115-121.

Ushirozawa, K., Tojo, Y., Takemae, S. and Sekiguchi, A. 1968. Studies on apple scar skin disease. 1. On transmission experiments. Bull. Nagano Hort. Exp. Res. Stn. 7:1-12 (in Japanese).

Vašková, D., Špak, J., Klerks, M. M., Schoen, C. D., Thompson, J. R. and Jelkmann, W. 2004. Real-time NASBA for detection of strawberry vein banding virus. Eur. J. Plant Pathol. 110:213-221.

Yang, X., Hadidi, A. and Hammond, R. W. 1992. Nucleotide sequence of apple scar skin viroid reverse transcribed in host extracts and amplified by the polymerase chain reaction. Acta Hortic. 309:305-309.

Zuker, M. and Stiegler, P. 1981. Optimal computer folding of large RNA sequences using thermodynamics and auxiliary information. Nucleic Acids Res. 9:133-148. 